\title{
Metaphor not as a stylistic but as a cognitive device: English language information technology manuals as a test case
}

\section{Agnès Corbisier}

\section{CpenEdition}

\section{Journals}

Electronic version

URL: http://journals.openedition.org/asp/4136

DOI: $10.4000 /$ asp. 4136

ISSN: 2108-6354

\section{Publisher}

Groupe d'étude et de recherche en anglais de spécialité

Printed version

Date of publication: 1 July 1994

Number of pages: 43-59

ISSN: 1246-8185

\section{Electronic reference}

Agnès Corbisier, « Metaphor not as a stylistic but as a cognitive device: English language information technology manuals as a test case », ASp [Online], 4 | 1994, Online since 20 January 2014, connection on 19 April 2019. URL : http://journals.openedition.org/asp/4136 ; DOI : 10.4000/asp.4136

This text was automatically generated on 19 April 2019

Tous droits réservés 


\title{
Metaphor not as a stylistic but as a cognitive device: English language information technology manuals as a test case
}

\author{
Agnès Corbisier
}

1 In the summer of 1991 I ran across Thomas H. Athey and Robert W. Zmud's Introduction to Computers and Information Systems (1988), which struck me as being a popularizing book I would like to read and might understand without outside help; this had not been the case until then, when I had tried to read, or simply use, other computer manuals. Four main features make the book an example of a handbook "designed for comprehension" (Streitz 1982: 11):

\footnotetext{
It prompts learners to read efficiently, i.e., "by means of objectives". Every chapter begins with an outline of its contents, and a short introduction in which the authors explain why the subject is relevant, how it relates to what has previously been learnt, and what the readers will "learn to do";

Detailed chapter summaries with key terms reviewed in context and end-of-chapter review questions allow learners to check their comprehension;

Full-colour illustrations are functionally interwoven with the text to explain and clarify it;

Athey and Zmud are acutely aware of the fact that people develop new cognitive structures from existing ones, by transferring meaning from one domain to another. Indeed, very often, to help the learner create an image of how the system works, besides illustrating the implicit metaphors contained in the very vocabulary of computer science with examples that relate the concepts to actual situations, they use more explicit verbal analogies than any other manual I have been able to find so far.
}

2 This has prompted me to try and answer the following questions: To what extent do explicit verbal metaphors clarify computer and information system concepts? What are the characteristics of effective verbal metaphors for information technology concepts? Are the implicit metaphors contained in the names given to some computer and 
information system concepts useful, useless or misleading? Do they work in the same way for English-speaking learners and for learners to whom English is a foreign language?

\section{Can explicit verbal analogies actually convey or clarify "hard" information technology concepts?}

3 In the field of human-computer interaction it is now often stressed that a computer user is both a problem-solver in a particular domain, who must have in mind a good model of what steps need to be taken to solve the problem, and an operator who must understand, i.e., mentally represent to himself how the machine works to make it perform as he wants it to. In other words, one reads a computer manual to form a mental model of how the machine works so as to be able to interact with it in the process of solving a particular problem in a given domain of reality.

But what is actually meant by "mental model", how does it function in the mental process of an individual and how is it formed?

The following definition may be useful. Adopting what he calls "critical realism concerning theoretical models", I.G. Barbour writes:

represent symbolically, for restricted purposes, aspects of a world whose structure is not accessible to us... Models are limited and inadequate ways of imagining what is not observable. They remain hypothetical; ...the 'as if' reflects both a partial resemblance and a tentative commitment. (1974: 37 - the italics are mine)

6 Two points are essential here: the idea that a model represents reality symbolically, and the idea that what it attempts to grasp is a structure. Th. Fawcett (1970) explains why all mental models - whether they are descriptive or analogical, whether they have limited relevance or have become control models - may come to have symbolic value:

Man has a twofold relationship with the world. On the one hand he is a physical entity and must live in a world of objects. On the other he is a spiritual being who must establish personal relationships. These two aspects of man's being confront the world in quite different ways. Any effort that man makes to understand the world as an It is accompanied by the fact that man himself is not only an It but also a Thou. Any worldview which he constructs, therefore, has importance at the subjective level. He has to live in the world as a person and so the descriptive and analogical models which he constructs usually have symbolic significance. He may attempt to conceive the world in purely objective terms, but he cannot escape his own subjectivity. (1970: 75)

7 If this is true, then when a model is being imagined, there must always be implicit or explicit reference to something familiar that has a similar 'structure'. Now, for I.T. users, the structure in an I.T. situation, i.e., a situation in which a goal has to be reached by doing something, actually rests on three pillar questions: what is performed by the system, how is it performed, and, possibly, why does it function as it does? A complete mental model of an I.T. situation includes these three questions.

8 Yet, from an experiment in which groups of subjects were given manuals containing varying amounts of detail, Y. Waern (1988) concludes that:

...users do not need complete models of the tasks they are to perform. Rather, they should have models furnishing enough information to solve a range of tasks which they might encounter. Thus it seems that it may be more helpful to prepare a system and a systems documentation to support the user's problem solving 
activities rather than trying to provide complete instructions covering every possible detail. (1988: 107)

In other words, in a learning-by-doing situation, task-oriented models answering the questions 'what' and 'how' may be sufficient. The 'why' question addresses the underlying structure of the system, and therefore mainly concerns system designers. Only fragments of the system's structure have to be understood by all users, for instance, that they have to save, to store in files, and that a file may get overwritten.

\section{How does a mental model function?}

10 When reflecting on the use of models in science, most philosophers identify the following functions: because they "simplify reality by leaving out irrelevant details, or by chunking concepts and procedures, thus reducing working memory load" (Waern 1988), models help us express the gist of what we understand intuitively. This enables us to compare our understanding with the actual system and to communicate our understanding to others, ${ }^{1}$ so that if there is a discrepancy between our model and either reality or other people's models, new conceptual activity will be triggered off, our model serving as a 'heuristic device'. ${ }^{2}$

11 Here is how I. Barbour (1974) explains why a model both helps to understand and to create:

...it gives in vivid form a summary of complex relationships... even at the critical stages of scientific discovery itself, scientists report that visual imagery often predominates over verbal or mathematical thinking, according to several studies. Images are creative expressions of the human imagination in the sciences as in the humanities. There are, of course, no rules for creativity; but it has been pointed out that analogies, models and metaphors are common in the search for new kinds of connection and new ways of looking at phenomena. (1974: 34) (italics mine)

Unfortunately, "the 'intuitive intelligibility' of a model is no guarantee at all concerning its validity" (Barbour 1974) and a user's model of a system may not correspond to the way it actually works or it may represent only one aspect of reality, i.e., be an answer to the question 'what', without answering 'how' and 'why', and therefore be of little use when (s)he is to operate the system. So, for instance, mentally modelling a wordprocessor as a typewriter often causes the user to run into trouble, ${ }^{3}$ although an experiment described by Waern (1988: 104-106) shows that it is a good metaphor to start with and when tasks resembling typewriter tasks are being performed.

\section{How are conceptual models formed?}

In the example of the word-processor model, the typewriter metaphor is clearly the expression of a model formed by analogy. Analogy is the source of both models and metaphors, which are obviously closely linked, so much so that the distinction between them may vanish. Following M. Black and M. Hesse, who "speak of theoretical explanation in science as "metaphoric re-description", I. Barbour discusses scientific models as "systematically-developed metaphors" because "similarities with a familiar situation are posited in some respects (the positive analogy), and differences are posited in other respects (the negative analogy),... even though the neutral analogy remains open for further exploration" (1974: 32 \& 44). J.M. Soskice, on the contrary, wants to keep the two categories distinct: a model can be distinguished from a metaphor because the latter 
is "a speaking about one thing or state of affairs in terms suggestive of another; a model need not be linguistic at all...Metaphors arise when we speak on the basis of models ... the presentation of a model, its linguistic presentation, that is, can take the form of a metaphor..." (1985: 101-102).

Unlike Solskice, MacCormac (1976) does not regard metaphors as the linguistic expressions of models but rather as the foundations of models:

Objectivity ...always involves the subject as he selects the aspects of human experience from which he will make, by analogy, assumptions ...These analogies expressed in root-metaphors then influence the way in which his explanations are constructed. (1976: 100)

Whether models are generated by metaphors or just expressed metaphorically, all philosophers agree that they are formed by analogy. In this respect, Th. Fawcett (1970) makes the following point. An analogical model is not simply an analogy:

It is called a model and not simply an analogy because this indicates that the analogy is being used to suggest a correspondence not merely between one particular thing and another but between one set of circumstances and another. The analogy is extended to cover a wider field. Sometimes the analogical character of a model is made explicit. It is not claimed that the model gives more than a partial insight, or assumed that it tells the whole story. In consequence, the use of one model does not preclude the use of others to illuminate the subject from a different point of view. (1970: 70)

16 In this respect, I would like to point out, though, that my experience is that instead of "illuminating the subject from a different point of view", using several non-integrated metaphors, or even more explicit analogies, to describe a system may hamper the construction of one single, consistent conceptual model.

In order to experience how metaphors can be useful when one tries to understand an information technology concept, let us compare Athey and Zmud's presentation of what a computer actually does with that made by A. Szymanski, D.P. Szymanski, N.A. Morris, and D.M. Pulschen in their Introduction to Computers and Information Systems (1991), another colourfully-illustrated popularising handbook, which, as far as reading is concerned, is as well "designed for comprehension" as Athey and Zmud's handbook, but seldom uses explicit verbal metaphors.

Here is how the authors deal with the subject:

... (Computers) can perform only three basic tasks:

1. Perform arithmetic functions on numeric data (adding, subtracting, mutiplying, and dividing)

2. Test relationships between data items by comparing values

3. Store and retrieve data

These tasks are really no more than people can do, but computers can accomplish the tasks faster, more accurately, and more reliably. [...]

Before a computer can begin any solution, the data must be presented. Data flow through a system according to the following general steps: (1) input, (2) processing, and (3) output. Data and information can also be stored during this flow.

Input involves collecting, verifying, and encoding data into a machine-readable form for the computer...

In processing, a computer creates useful information from data through such operations as classifying, sorting, calculating, summarizing, and storing...

Output includes retrieving data, converting them into human-readable form, and displaying the information to the user. (Szymanski et al. 1991: 10-11)

19 The same idea is explained as follows by Athey and Zmud: 
...The computer is merely processing information. But what exactly do we mean by "processing information"? ...To understand this, it may help to look first at how people process information.

At one time or another, you have probably worked a crossword puzzle. Solving a crossword puzzle is purely an information processing activity. Using the puzzle shown in Exhibit 1.15, consider the steps you would go through in solving it:

1 . Read the clue given in " 1 across". This involves identifying each of the letters and numbers making up the clue.

2. Combine these symbols to interpret and understand the clue.

3. Try to relate the clue to a fact or concept you may have in your memory.

4. Produce an answer.

5. Try to match the letters in your "correct" answer to the spaces provided.

6. If the number of letters match, write this answer in the spaces provided.

If the number of letters do not match, go back to step 1.

Step 1 required you to enter some data into your mind. Step 2 required you to process these data in order to interpret the clue. Step 3 required you to retrieve some data or information previously stored in your memory. Step 4 required you to process all the data and information now active in your mind in order to produce a new set of symbols representing your answer to the puzzle clue. In step 5, you tested your answer by seeing if it fit into the puzzle spaces. Step 6 required you either to transfer your answer to the clue onto the puzzle or to go back to Step 1. In this information processing task, you engaged in a number of input, processing, storage and retrieval, and output activities.

These stages of input, processing, storage and retrieval, and output activities are exactly what a computer does when it processes information. (1988: 18-19)

It is obvious how effective this explicit verbal metaphor is in helping the learner conceptualize. So, just as in the "arts", the metaphor can play a vital role in helping the human mind give a more 'tangible' shape to information technology realities that cannot be grasped by the human eye.

\section{What are the characteristics of effective verbal metaphors for information technology concepts?}

In the above-mentioned example, the authors do not merely point to the analogy that exists between a human being solving a crossword puzzle and a computer processing information. They describe the meaning transfer they want it to facilitate. Why? Undoubtedly, because, unlike literary metaphors, which are considered to be all the richer if they can be interpreted differently by different individuals, explanatory ${ }^{4}$ scientific metaphors have to convey a single accurate concept. Hence, if they are not used cautiously, they may lead to conceptual errors. That is why it is important to explain what matches what, and, possibly, to point out the differences with the real system of which one is trying to give an image. In other words, when one explains scientific notions, the limits of the metaphor have to be highlighted.

So, for instance, after comparing a computer's problem-solving process with the procedures involved in baking a pie, where data or ingredients are assimilated to input to be processed according to a computer program or recipe in order to give an outcome that satisfies a need, i.e., a baked pie or information, Athey and Zmud write:

There are several key differences between the baking analogy and actual computer processing. One is that the oven is a rather simple single-purpose machine. Computers are general-purpose machines that can be instructed to do a variety of tasks, such as ... The second difference is that, while recipes contain step-by-step 
procedures, this type of instruction would not be specific enough to direct a computer. For example, the recipe assumes you had or would get the ingredients and utensils needed to perform each instruction. Furthermore, some of the instructions are unclear and need interpretation. You are advised to "creambutter and sugar until light", but how light is "light"? ...The instructions in recipes leave gaps that must be filled by experience and interpretation. Computers have neither of these skills... [they] need algorithms. (1988: 67)

Szymanski et al. 1991: 52) or an “office manager who assigns work to a computer system's different components and who also helps out with the more important and difficult tasks" (Athey \& Zmud 1988: 16) ${ }^{5}$ does not help much in figuring out how it works. But the following analogy makes things much clearer:

\begin{abstract}
A program called a supervisor, executive, or monitor exercises overall master control of computer operations and coordinates work within the computer system. The way an OS exercises master control is, in many ways, similar to what you may have experienced when you visited a doctor with a large practice. You wait with the other patients in the outer waiting room. When one of the examining rooms is free, the nurse asks the next patient to enter it.

There are a number of examining rooms in which patients wait to be examined by the doctor. When the doctor completes the examination of one patient, he or she then goes into the examining room occupied by the next patient. The doctor then calls in the technician to take the patient to X-ray. When the X-rays are ready, the doctor will begin the exam at the point at which he or she left off. In the meantime, while waiting for X-ray results, the doctor goes into the examination room of the next patient and begins the examination. [...]

In computer systems, the CPU is analogous to the doctor. In other words, the CPU is where the real work gets done. The CPU can process only one program at a time, just as the doctor can see only one patient at a time. The CPU works on one program until it is either completed or there is a need for input/output (I/O) data such as reading data from a computer terminal or sending data to the printer. Then it is directed by the OS to go on to the next scheduled program in primary memory. The head nurse functions as the overall supervisor of what gets done, when, and by whom. For computers, the operating system performs this overall control function. The outer office waiting room is analogous to application programs waiting on disk to be read into primary memory and executed. The OS decides which of these programs should be loaded into primary memory next using predefined rules. Primary memory, like the inner examining rooms at the doctor's office, is divided into areas that can hold different programs.

...The supervisor plays a major role in deciding which programs get run, and when. But the OS is not an autonomous unit. Rather, it is carrying out policies set by the data processing center management or programmers. (Athey \& Zmud 1988: 183)
\end{abstract}

No doubt, what makes the analogy effective is that the authors explicitly indicate what matches what. Yet, it should be noted that it is effective for readers who have already visited a doctor "with a large practice" or in a hospital. Without that world knowledge, it is unlikely to be very helpful, unless the verbal analogy is enhanced by a picture or a diagram that allows the reader to visualize the idea. In other words, to be effective for a great number of 
people, the analogies used should either be part of most people's world knowledge, or be presented visually, so that the reader spontaneously generates a definite image. The following examples illustrate this point. Although it may not be necessary, both are supplemented by pictures, which reinforce the power of the verbal metaphor.

Here is how Athey and Zmud explain how data and instructions are located by the control unit of the central processing unit:

RAM primary memory is used for temporarily storing user's program instructions and data...The control unit will handle the task of finding that information.

To do this, the control unit maintains a map of primary memory in much the way that streets are mapped. As shown in Exhibit 3.10, both maps and memory chips are made of grids formed by the intersection of horizontal and vertical lines. Each intersection is assigned a set of coordinates. If you look up the entry South Street in the map index, for example, its coordinates would be $\mathrm{C} 4$. To find this location, you would look down the left side of the map until you located sector $C$. Then you would proceed horizontally until you reached sector 4. Primary memory addressing works in a similar fashion. Assume, for example, that our computer has $64 \mathrm{~K}$ of primary memory. $\mathrm{K}$, or kilo, is an abbreviation for kilobyte, or 210 , or 1024 bytes. A $64 \mathrm{~K}$ memory would be arranged in a grid of 256 rows by 256 columns. Each address, or intersection on this grid, could be found by using two coordinates, one for the particular row and one for the particular column.

In computers that have larger amounts of primary memory, the RAM chips are arranged in banks, and the bank number is added to the address. This is similar to using a set of maps to represent a large area. For example, the city map for a large city might give the address of South Street as page 17, coordinates $4 \mathrm{C}$ (Athey \& Zmud 1988: 79-80).

I do not think the subject could be explained better than it is here. The metaphor is all the more effective as there is partial isomorphism between both the object and action in the metaphor and in the "source" domain (Carroll \& Thomas 1982: 111). Besides, the isomorphism is highlighted by the "exhibit".

Another example of what could be called perfect "congruence" (Carroll \& Thomas 1982: 111) between a technological concept and its metaphorical representation is Athey and Zmud's presentation of a major advance in memory management, called "virtual memory using demand paging":

To understand how demand paging works, consider the following analogy. When studying this textbook, you use, at any one time, only several pages out of the total number available. You could be actively reading one page, on which a certain paragraph could refer you to a diagram on the next page. Later, you may need to turn to the glossary to look up the definition of a term introduced in a previous chapter. When you have finished studying, or completed processing, the page, you then turn to the next page.

In a similar way, programs can be subdivided into sections containing instructions. These sections are of a fixed length and are called pages. With previous memory management schemes, the complete program had to reside in primary memory for processing to be accomplished. The concept of virtual memory means that only relevant pages need to be in primary memory at any one time, while the remainder of the program is stored on disk, available on demand (see Exhibit 7.9). (Athey \& Zmud 1988: 186)

The concept of "virtual" memory, the very congruence between the concept and its name, ${ }^{6}$ is further explained by Athey and Zmud in the comment accompanying Exhibit 7.9: 
An advanced memory management technique, virtual memory, makes it appear that primary memory is of unlimited size and can therefore readily accommodate very large programs. Primary memory and disk memory are both divided into locations of a fixed page size. Program A has been divided into 10 pages, which are stored on disk. Pages A-1, A-7, and A-10 are actively being processed in primary memory. When, in processing the instructions of Program A, it becomes necessary to get a new Page, A-4, for example, it could be swapped for Page A-10. But a problem comes about if A-10 is later needed along with Pages A-1, A-7, and A-4. Since all other memory locations are occupied by other programs, one of the A pages, which will be needed very soon, is swapped. When A-4 replaces A-10, and moments later Page A-10 must be referred to for information, another swap will have to take place. When a large portion of CPU time is used shuffling pages back and forth from disk to primary memory, the system is said to be thrashing. (Athey \& Zmud 1988: 187)

Although the reading metaphor is quite appropriate, since there is a perfect analogy between what the demand paging technique does and what any reader does, I wonder why the authors have not stuck to the initial image of primary memory they had given, namely that of a map-book. Demand paging could have been explained on the basis of that map book, which would have given the reader a better view of the interaction between CPU, primary memory and disk.

The same can be said about the various ordinary-life images the authors use to represent the functions of the operating system: a traffic cop, an office manager, a head nurse (see above). The idea that the set of programs called "supervisor, executive or monitor" controls and coordinates work within the computer system has certainly been conveyed but, in my view, having three different images does not help in any way, and may even cause confusion. Besides, none of these images is further used to explain virtual memory using demand paging or the interaction between operating system, primary memory, virtual memory, and central processing unit, for which there is no metaphorical representation.

33 In other words, as a learner, I would have had a better overview of how a computer system as a whole works if all the metaphors used to describe it had been drawn from one single ordinary-life domain, whether it be a police station, an office or a hospital.

\section{Are the implicit metaphors contained in the names given to some computer and information system concepts useful, useless or misleading?}

Do they work in the same way for English-speaking learners and for learners to whom English is a foreign language?

A striking feature of information technology vocabulary is the number of words that implicitly call images of ordinary life to mind. On the face of it, this should help to understand the concept, and it often does, if by understanding you mean knowing what the system is for, not how it works. Indeed, the fact that the images that arise from the names are so close to ordinary-life concepts may even cause interferences, and lead to errors because the user is misled into thinking that there is no difference between what he knows and the new system. So, for instance, observing people who are learning to use a word processor shows how often the image of the typewriter interferes with their use of a word processor. ${ }^{7}$ Learning to use electronic mail and voice mail is likely to lead to the 
same kind of interference, especially if people are taught to use the system or software without first explaining how the computer system as a whole works so that real comprehension, i.e. the construction of an internal representation of the system, is impossible. Here follows an example of a manual "intended to teach people who have no experience with computers how to program instructional lesson materials in the TenCore language" (Computer Teaching Corporation (1989: 1). The authors are aware of the difficulty and have endeavoured to design the handbook so as to promote understanding:

As with learning a foreign language, the most efficient way to learn is to practise. Memorising the syntax and vocabulary of the language is not only inefficient, but also very frustrating. The approach used in this book is to explain new features of the language in the context of a particular problem. Examples are used to facilitate the development from the most basic concepts in TenCore to some of the more complex features.

Besides, each chapter begins by setting objectives, which is known to promote effective reading, and ends with exercises allowing the reader to review and practise at the same time. So, a well-designed manual, except that the novice programmer for whom the book claims to have been designed is unlikely to be able to form an internal representation of how the system works after reading the following introduction:
To start using the TenCore System you'll have to get your computer running and TenCore started. After "booting" your computer you will see a prompt similar to C: $\backslash$. This is the DOS prompt. If TenCore has not been installed on your computer, refer to the TenCore Operating System manual for instructions on how to install the TenCore system. To start using TenCore type 'author' at the DOS prompt. In a few seconds you will see the TenCore Title Display. (Computer Teaching Corporation (1989: 4)

There is not one word about what an operating system actually does in a computer system. Can a user be expected to learn how to do something, without understanding why? Yes, certainly. It is even often the case with practical skills that are acquired "by doing", and using information technology, whether it is data/information processing or communication, is a practical skill many acquire heuristically, by trial and error, without really understanding, i.e. having in mind a representation of what is actually taking place. This is all the more feasible as the mental representations triggered by much of the vocabulary actually give one the comfortable impression that one understands how the system functions.

Indeed, unlike most other specialist domains, information (processing and communication) technology uses jargon that sounds easy because it has been developed on the basis of the analogy with human everyday-life activities, namely, problem-solving and communicating, so that most of the names given to concepts have been borrowed from the language that describes human intellectual or communicating activities. In other words, information technology has coined fairly few "new jargon" words to describe what actually happens inside the machine or between machines.

Now, this is a double-edged sword. In fact, what often happens is that one thinks one understands because one can conceptualize the function on the basis of the verbal description one is given. Yet, the way people process information is unique, different, ${ }^{8}$ and only vaguely understood, so that the verbal descriptions of human information processing are vague and abstract, while the processes described are the result of scientific and technological accuracy. In other words, there is a semantic discrepancy, a "meaning gap" between the "names" and the "objects named": the name gives one the 
impression that one understands but the internal representation one forms is too vague for one to "see" the real phenomenon.

Consider for instance the following summary given by Athey and Zmud (1988: 89), at the end of the chapter explaining how computers work:

To process information, a computer needs very specific instructions that explicitly state what is to be done... [These] are called algorithms.

The computer processor unit is made up of a CPU and primary memory. The CPU contains the arithmetic-logic unit (ALU) and a control unit. The ALU is where all arithmetic and logic operations are performed. The control unit is used to sequence computer events according to program instructions, such as moving data between primary memory and the CPU or between input/output devices and primary memory. Primary memory is used to hold data and program instructions.

The control unit is composed of a program counter, instruction register, instruction decoder, and address register. Registers are storage locations within the CPU that are used as temporary staging areas. The ALU is composed of several registers, one of which functions as an accumulator to store ongoing results...

41 Although this is a very detailed summary, in which almost every word spontaneously suggests a well-known image (e.g., memory, control, counter, register, storage), one cannot form an internal representation of the system on the basis of these words, for: what does memorising, controlling, counting, registering, storing actually mean for a computer? Without the crossword puzzle and the map metaphors mentioned above, as well as the illustrations provided both by means of examples relating the concept to actual situations and by means of numerous "exhibits" (diagrams, or pictures), I would not have understood.

Obviously, accurate understanding, i.e., having/forming a mental model of how the system actually works is what it takes to be an information technology expert capable of interacting with the system in order to solve problems and, for instance, design information systems.

Now, for people who need/want to understand (new) information technology concepts thoroughly, and, to whom English is not the language in which they spontaneously create mental models, there is the additional problem that they often have to learn concepts in a foreign language, in which they are not aware of the semantic field of the "name" given to a concept so that the "meaning gap" between "name" and "object named" is even wider. Translating the word, especially into French, which is a more abstract language than the Germanic languages, often fails to bridge the gap. It may even widen it.

Recently, a French-speaking information technology expert submitted to me the following excerpt from a book about artificial intelligence:

The frame problem: To use a familiar analogy, the changes between one state description and another can be compared to changes between frames in an animated film. In very simple animations, certain characters move in a fixed background from frame to frame... The problem of specifying which well-formed formulas in a state description should change and which should not is usually called the frame problem in AI. (Nils 1982: 279)

His query was: "what is a frame actually?". So, the analogy with animated films had not worked, which is not really surprising since it is not very explicit. And, as he was not aware of the semantic field of the word "frame", the translation "structure" was not concrete enough for him to be able to form a mental model of what was meant. As a Germanic language philologist, I immediately associated the word with a window-like 
structure inside which there can be different states or actions (cf. raam in Dutch, Rahmen in German).

Another example is the word 'engine', which in expert systems describes the set of inference rules with which a domain expert uses his knowledge and expertise. Why 'engine'? Because it is the result of the knowledge engineer's work, i.e. the work of the system analyst skilled in developing expert systems. If the link between engine and engineer escapes one's attention, or if one translates "engine" into "moteur", one's mental model of how an expert system functions is less clear because the "meaning gap" is wider. Another clear example illustrating that translating does not help form a mental model is the translation of the word "bug": "bogue". If you know the word "bug" in everyday American English, the meaning is clear: a bug is any small insect, hence something that causes trouble, hence, something wrong with a machine. But what is a "bogue" in everyday French? The husk of a chestnut, which, if one is the victim of a joke, may, indeed, occasionally be experienced as a prickly embarrassing object. Yet, if the image had not been suggested to me by an expert in the analysis of metaphors, Professor van Noppen, I would not have produced it. 'Bogue' was to me, as it is to most computer users just an onomatopoeia of 'bug'. But while, to native speakers or linguists, 'bug', like 'frame', are living metaphors, i.e., verbal presentations that call to mind a model, to EFL computer users, unless it is explained, the "web of implications" (Soskice 1985: 73) is often entirely lost.

The conclusions of this introductory study of the use and function of metaphor in information technology can be summarized as follows. Metaphors are essential to convey and/or clarify information technology concepts. They are often used to help the reader form a mental model of at least what an I.T. system does, but to be really effective, they should also help the reader form a mental model of how the I.T. system works. This requires that I.T. explanatory metaphors should be explicit, delimited, part of the reader's world knowledge, and congruent with the structure to be modelled. Of course, pictures and (partial) isomorphism between the reality from which the metaphor is derived and that of which one is trying to give an image reinforce the power of the verbal explanatory metaphor.

Since explanatory metaphors are meant to be conducive to one single conceptual model, my contention is that they should draw on as few analogies as possible. The more similarities there are between the familiar reality and the one that is to be modelled, the more comprehensive the metaphor is, the more effective it is.

Regarding IT vocabulary, the few examples I have examined so far prompt me to say that, vague though they may be, the living metaphors contained in the names that describe I.T. concepts had better be explained rather than translated, because more often than not translating a name kills the metaphor. 


\section{BIBLIOGRAPHY}

Athey, T.H. and R.W. Zmud. 1988. Introduction to Computers and Information Systems. Glenview Ill.: Scott, Foresman \& Co.

Barbour, I.G. 1974. Myths, Models and Paradigms: The Nature of Scientific and Religious Language. London: SCM Press.

Carroll, J.M. (ed.). 1982. Interfacing Thought: Cognitive Aspects of Human-Computer Interaction. London: Taylor and Francis.

Computer Teaching Corporation. 1989. Introduction to Tencore.

Fawcett, T.H. 1970. The Symbolic Language of Religion. London: SCM Press.

MacCormac, E.R. 1976. Metaphor and Myth in Science and Religion. Durham, N.C.: Duke University Press.

Nils, J.N. 1982. Symbolic Computation: Principles of Artificial Intelligence. Berlin \& New York: Springer Verlag.

Soskice, J.M. 1985. Metaphor and Religious Language. Oxford: Oxford University Press.

Szymanski, R.A., N.A. Morris and D.M. Pulschen. 1991. Introduction to Computers and Information Systems. New York: MacMillan.

Waern, Y. 1988. Cognitive Aspects of Computer-Supported Tasks. Chichester: John Wiley \& Sons.

\section{NOTES}

1. Cf. Mary Hesse quoted by I. Barbour: "Models, like metaphors, are intended to communicate. If some theorist develops a theory in terms of a model, he does not regard it as a private language, but presents it as an ingredient of his theory". (1974: 43)

2. Braithwaite's stance reported by I. Barbour.

3. See my account of the "Word" workshop held by Professor Ducamp - ULB.

4. I.e., not the heuristic scientific metaphors which lead to new discoveries thanks to a certain amount of vagueness and poly-interpretability.

5. The authors are aware that this cannot be a very effective analogy. They use it in the introductory chapter, in the general presentation of what a computer is, and somehow give to understand that this is not the whole picture by writing: "For now, think of the operating system as an office manager...".

6. The Concise Oxford Dictionary defines "virtual" as follows: "That is such for practical purposes though not in name or according to strict definition".

7. Between October and December 1990, I had the opportunity of observing novice users of a wordprocessor who were learning to use Word 4, by themselves, i.e., with the manual as a guide. The learners were non-European university graduates who had enrolled at the ULB in the Postgraduate Pédagogique en Informatique appliquée aux Sciences de l'éducation, and to whom English was a foreign language. The objective of the workshop set up by Professor A. Ducamp (ULB, Faculté des Sciences Psychologiques et Pédagogiques) was to try and assess to what extent 
the knowledge of English played a more or less important part in their being able to learn to use a software programme autonomously, from a manual written in English. Two groups of students were formed. One group was given a manual in English and the possibility of having parts of the text translated by me acting as a resource person, while the other students received the same manual translated into French, which all the students were supposed to know before embarking on the postgraduate course. The experiment described in "Étude exploratoire sur les connaissances d'anglais dans l'apprentissage de l'informatique par des sujets non-anglophones", mémoire présenté par N.L. Colorado, shows that learners stumbled on the same kind of difficulties, whether they were working with an English or a French manual. The obstacles to self-training were not linguistic ones but rather the fact that they had no image or a wrong image of how a word processor works.

8. See Athey and Zmud: "Our ability to work with incomplete sets of data and to generalize meanings across sets of data is very powerful. Most important, however, is our ability to create. When we are faced with a problem, we are often able to arrive at a solution by piecing together prior experiences, sketchy facts, and human intuition. Computers, on the other hand, are limited to a few rather basic processing operations (p.22): simple arithmetic operations such as addition, subtraction, multiplication, and division, and simple logic operations, such as comparing". (1988: 21)

\section{ABSTRACTS}

Acting as a resource person for English in a workshop whose objective was to try and assess to what extent the knowledge of English played a more or less important part in learners being able to learn to use software autonomously, I observed that the obstacles to self-training were not linguistic ones but rather the fact that the learners had no image or the wrong image of how a word processor works. But what is actually meant by 'mental model' of an I.T. system or computer-supported task? How does it function in the mental process of a user? And how is it formed? To what extent do explicit verbal metaphors clarify computer and information system concepts? What are the characteristics of effective verbal metaphors for information technology concepts? Are the implicit metaphors contained in the names given to some computer and information system concepts useful, useless or misleading? Do they work in the same way for English-speaking learners and for learners to whom English is a foreign language? These are the issues I propose to approach in my paper.

Agissant en tant que personne ressource dans un atelier dont l'objectif était d'essayer d'évaluer dans quelle mesure la connaissance de l'anglais jouait un rôle plus ou moins important dans le fait que l'on soit capable d'apprendre à utiliser un logiciel de manière autonome, j'ai observé que les obstacles à l'auto-apprentissage n'étaient pas linguistiques mais plutôt le fait que les apprenants n'avaient pas ou avaient une image fausse de la manière dont fonctionne un traitement de texte. 
INDEX

Mots-clés: métaphore, technologie de l'information

Keywords: information technology, metaphor

\section{AUTHOR}

\section{AGNÈS CORBISIER}

Agnès Corbisier teaches at Université Libre de Bruxelles, Section Informatique et sciences humaines. agnescorbisier@skynet.be 